\title{
A SIMPLE SYSTEM TO DETECT AND MEASURE FORMALIN IN FRUIT BY USING CONDUCTIVITY, pH AND CAPACITANCE MEASUREMENT
}

\author{
MD.Shahidul Islam ${ }^{1 *}$, MD.Mehrub Hasan', Ainul Anam Shahjamal Khan', Muhammad Abu \\ Bakar $^{2}$ \\ ${ }^{1}$ Department of Electrical and Electronic Engineering, \\ Chitagong University of Engineering and Technology, Chittagong-4349, Bangladesh. \\ ${ }^{2}$ Bangladesh Council of Scientific and Industrial Research, Chittagong-4220, Bangladesh.
} shahideeecuet@gmail.com

\begin{tabular}{|c|c|}
\hline Article history: & \multirow{12}{*}{$\begin{array}{l}\text { ABSTRACT } \\
\text { Economically motivated adulteration (EMA) of food is becoming } \\
\text { common in some developing countries. Formalin is a harmful } \\
\text { organic chemical substance which is often used by businessmen to } \\
\text { keep their fruits etc. look fresh for longer times. It consists of two } \\
\text { substances: formaldehyde and water. Formalin is used for long time } \\
\text { preservation for various types of foods and other things from } \\
\text { putrefaction. It affects human life as well as environmental ecology. } \\
\text { At present, EMA by Formalin is becoming severe in countries like } \\
\text { Bangladesh. Formalin detection is a challenging task. Most of the } \\
\text { techniques to detect formalin are based on chemical sensors. The } \\
\text { paper aims at detecting formalin in fruits by electrical properties such } \\
\text { as conductivity and capacitance together with cheap pH sensor. The } \\
\text { fruits are immersed in distilled water and conductivity, capacitance } \\
\text { and pH of the water are measured. The result is very promising with } \\
\text { an average error of } 7.18 \% \text {. For higher concentration the average error } \\
\text { is } 5.02 \% \text {. Although the proposed method does not give result } \\
\text { instantaneously, but it could lead to a method of detecting formalin } \\
\text { mainly based on electrical properties in future. }\end{array}$} \\
\hline Received: & \\
\hline Accepted: & \\
\hline 28 March 2019 & \\
\hline Keywords: & \\
\hline Formalin; & \\
\hline Distilled water; & \\
\hline Capacitance; & \\
\hline Conductivity; & \\
\hline & \\
\hline Detection & \\
\hline Quantity measurement. & \\
\hline
\end{tabular}

\section{Introduction}

Economically motivated adulteration (EMA) is increasing tremendously in some countries in the name of preservatives. The people of developed country do not agree with the use of food additives at all (Zugravu et al., 2017). Detecting adulteration of fruits and fruitderived products often requires costly equipment and complex process (Sobolev et al., 2015). Formalin is an aqueous solution of formaldehyde that is 37 per cent by weight, usually containing 10 to 15 per cent methanol to prevent polymerization of the formaldehyde. It is used in the manufacture of resins, textiles and as a laboratory fixative or preservative. But formalin is used by some businessman in countries like Bangladesh to preserve fruit for longer time. This practice is widespread now. This practice is severely dangerous (Ali, 2013). So detection of formalin is growing more attention in order to take preventive measures for public health safety.

Formalin detection using chemical and optical properties requires costly sensors and equipment (Möhlmann, 1985; Tang et al., 2016) as well as complex methodology. Detection method of formalin based on electrical properties could be a better solution because it 
does not need any chemical sensor or reagents. For this purpose some researchers have tried in different ways. Development of portable electronic reader was proposed (Hashim et al., 2015) for detection of formaldehyde gas sensor. This electronic reader can detect the level of formaldehyde concentration, which later translated into voltage level. Three level of detection is possible such as high, medium and low concentration of gas respectively but exact quantitative measurement is not reported. To detect formalin based on optical characteristic, refractive index (Arif et al., 2016) is chosen for analysing through simulation. They used Photonic Crystal Fiber (PCF) based Formalin sensing technique. Their study reveals the refractive index of Formalin along with a proposal of a PCF structure for Formalin sensing but it was not implemented practically. Conductivity of formalin changes with the change of concentration of formalin (Hasan et al., 2014). This kit performs using only one property. Three level of detection is possible without exact quantitative measurement by this kit. A variable-temperature variable-thickness interferometer (Khan et al., 2007) was assembled to perform dispersive Fourier transform spectroscopy (DFTS) on liquids at millimeter and sub millimeter waves. During testing $10 \%$ formalin and 1,4-dioxane, they first used DFTS for environmental and biological applications. If formalin's broadband dielectric properties and signatures are known, spectroscopic analyses of preserved biological tissues can be done to identify potentially malignant or cancerous tissues.

Some methods discussed above are complex, some do not show conclusive results and some are still in simulation level. This led us to endeavor a method which would be simple yet provide conclusive result. We proposed a simple hybrid method of detecting formalin in fruit mainly based on electrical properties and only one chemical property. The primary results showed promising performance. To our knowledge, no studies have done so far in this way to detect formalin adulteration in fruits.

\section{Materials and methods}

\subsection{Materials}

Formalin has some distinct characteristic. We have used $\mathrm{pH}$, conductivity and capacitance to detect and measure quantity of formalin in test solution. Conductivity varies for different concentrations of formalin. $\mathrm{pH}$ decreases from 7 ( $\mathrm{pH}$ of distilled water) if formalin exists. At different concentration of formalin, capacitance changes from picofarad to microfarad range.

\subsection{Conductivity measurement:}

For conductivity measurement we have used Wheatstone bridge circuit (Coughlin et al., 2001).This is a simple technique for conductivity measurement. Actually we transformed change in conductivity to change in voltage using the circuit (Figure 1).

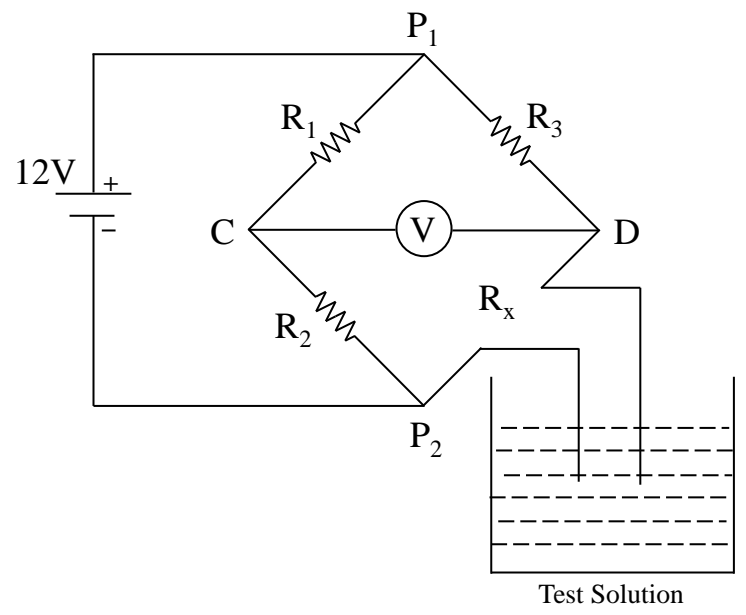

Figure 1. Wheatstone Bridge circuit

There are four resistors in our bridge circuit. They are $R_{1}, R_{2}, R_{3}$ and $R_{x} . R_{1}, R_{3}$ are simple $2 \mathrm{~W}, 1 \mathrm{M} \Omega$ resistor. $\mathrm{R}_{\mathrm{x}}$ is the unknown resistance of water. The current through the multimeter depends on the potential difference between $\mathrm{C}$ and $\mathrm{D}$. When the potential difference across the multimeter is zero, this is called null condition. It is acquired by adjusting potentiometer $R_{2}$.

From the figure,

The voltage at point $\mathrm{D}$,

$V_{\mathrm{D}}=V \times R_{X} /\left(R_{3}+R_{X}\right)$

The voltage at point $\mathrm{C}$,

$V_{\mathrm{C}}=V \times R_{2} /\left(R_{1}+R_{2}\right)$

The voltage $(\mathrm{V})$ across galvanometer or between 
$\mathrm{P}_{1}$ and $\mathrm{P}_{2}$ is,

$$
\begin{array}{r}
V_{D C}=V \times R_{X} /\left(R_{3}+R_{x}\right) \\
-V \times R_{2} /\left(R_{1}+R_{2}\right)
\end{array}
$$

When the bridge is balanced i.e. $V_{\mathrm{D}}=V_{\mathrm{C}}$, then $V_{D C}=0$

There is an almost linear relationship between concentration of formalin and conductivity. If the concentration of formalin increases, it decreases resistance and increases conductivity. This changes RX, which changes $\mathrm{V}_{\mathrm{D}}$, the bridge becomes unbalanced and $\mathrm{V}_{\mathrm{DC}}$ has some value which is actually a function of concentration of formalin.

\section{3. pH measurement:}

Formalin has a distinct $\mathrm{pH}$ characteristic. So detection of formalin can be performed by using a $\mathrm{pH}$ sensor which gives output voltage according to $\mathrm{pH}$ of the solution. The $\mathrm{pH}$ of formalin is less than water's pH i.e. 7.

At different concentration of formalin, $\mathrm{pH}$ of the solution varies from 2 to 6.2. When we added $0.02 \mathrm{cc}$ formalin to $100 \mathrm{ml}$ distilled water, we found $\mathrm{pH}$ 6.2. When we gradually mixed formalin with $100 \mathrm{ml}$ distilled water, $\mathrm{pH}$ value decreases.

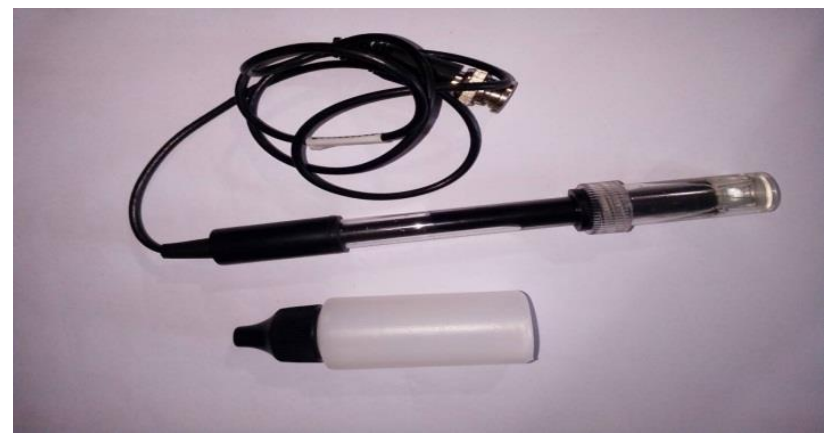

Figure 2. $\mathrm{pH}$ Sensor

\subsection{Capacitance measurement:}

Formalin has distinct capacitive characteristic. Normal water shows dielectric constant of 80 . But formalin shows dielectric constant of 23. We have used parallel plate used for Printed Circuit Board (PCB) after some modification to measure the capacitance of formalin. Parallel plates are insulated by using color spray to reduce the conductive effect.

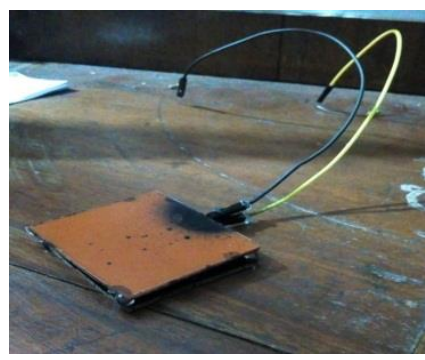

Figure 3. Practical Implementation of parallel plate capacitor using $\mathrm{PCB}$

The detection circuit used for this study used auto range detection schemes for different ranges of capacitors. We used Arduino Mega for measuring capacitance. Each capacitance meter has an RC circuit with known resistor values and an unknown capacitor value. The Arduino measures the voltage at the capacitor and record the time it takes to reach $63.2 \%$ of its voltage when fully charged. This time is known as time constant. Since the resistance value is already known, we can easily measure capacitance.

We charged the capacitor through a resistor using one of the Arduino pins. Using the ADC of the Arduino, we measured the voltage that the capacitor reached. Arduino started to measure time to reach the $63.2 \%$ of the full voltage. We used the following $\mathrm{RC}$ circuit for measuring capacitance.

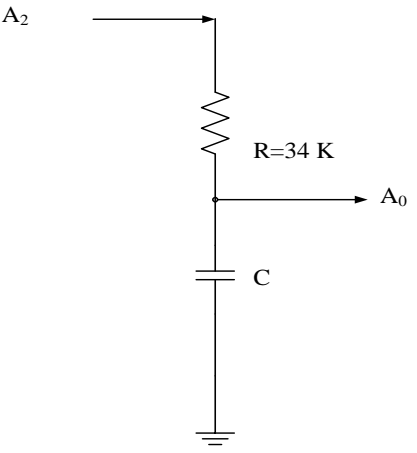

Figure 4. Capacitance measurement Circuit

The internal pull up resistance of the Arduino was used as the resistor of the RC network. It has a value of around $34 \mathrm{k} \Omega$. A 5 volt 
supply was placed at $\mathrm{A}_{2}$ and the voltage at $\mathrm{A}_{0}$ was sampled along with the time. The value of test capacitance was calculated from (Wahid et al., 2014)

$$
C=\frac{-t}{R \ln \left(1-V_{A 0} / V_{A 2}\right)}
$$

Table 1. Comparison of measured capacitance using Arduino with nameplate value of capacitance

\begin{tabular}{|c|c|c|}
\hline $\begin{array}{c}\text { Capacitor } \\
\text { (nameplate } \\
\text { value) }\end{array}$ & $\begin{array}{c}\text { Capacitor } \\
\text { (measured } \\
\text { using Arduino) }\end{array}$ & $\begin{array}{c}\% \text { of } \\
\text { Error }\end{array}$ \\
\hline $10 \mathrm{pF}$ & $11.72 \mathrm{pF}$ & 17.2 \\
\hline $100 \mathrm{pF}$ & $78.5 \mathrm{pF}$ & -21.5 \\
\hline $1 \mathrm{nF}$ & $0.92 \mathrm{nF}$ & -8 \\
\hline $10 \mathrm{nF}$ & $11.09 \mathrm{nF}$ & 10.9 \\
\hline $100 \mathrm{nF}$ & $107.50 \mathrm{nF}$ & 7.5 \\
\hline $1 \mu \mathrm{F}$ & $1.08 \mu \mathrm{F}$ & 8 \\
\hline $3.3 \mu \mathrm{F}$ & $3.8 \mu \mathrm{F}$ & 15.1 \\
\hline $10 \mu \mathrm{F}$ & $9.74 \mu \mathrm{F}$ & -2.6 \\
\hline
\end{tabular}

Readings were taken for various capacitors available in market and in each case the readings were within a tolerance limit of $25 \%$. The readings along with errors of the system for various ranges of capacitors are listed in the "Table 1".

\subsection{System algorithm:}

We immersed the sample fruit in distilled water for 10 minutes. Then we take out the fruit. The remaining water is our test solution. We start our detection procedure by determining $\mathrm{pH}$ of the test solution. It indicates the existence of formalin in test solution. If $\mathrm{pH}$ is greater than 5.5 , then it indicates that there is no formalin. If $\mathrm{pH}$ is less than this limit, it demonstrates the existence of formalin in test solution.

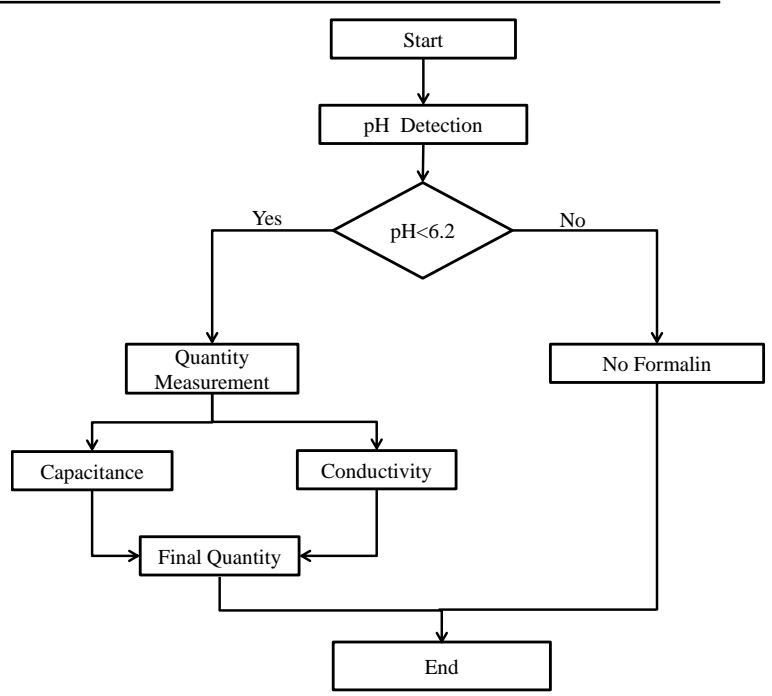

Figure 5. Algorithm of the system

Then it performs the quantity measurement. Our detection algorithm uses two parameters. It analyses quantity using the capacitive and conductive property. Using those properties, our detection system analyzes final value and shows result.

We implemented final circuit by arranging all the three individual parameter-based circuits. For correlating all the three parameter-based circuits, we went through numerous trial and errors. Finally we fine-tuned the program which best correlates the detected formalin concentration with known samples. After calibration, we measured the existence and quantity of the formalin.

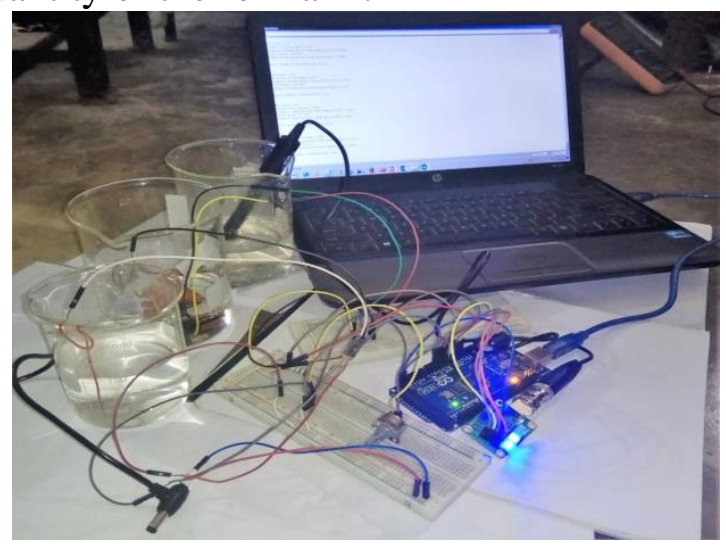

Figure 6. Photo of final implemented system 
3. Results and discussions

3.1. Formalin concentration measurement using conductivity circuit:

We used Wheatstone bridge circuit for conductivity measurement. At balance condition, when there was no formalin existed in the solution, the output voltage became zero. Then we added $0.02 \mathrm{cc}$ formalin to $100 \mathrm{ml}$ distilled water.

Formalin is a conductive solution. So, when formalin was added to distilled water, the resistance of water decreased which made the bridge unbalanced. So the voltage difference of bridge circuit increased. So we got an unbalanced voltage output of 2.19 volt. When formalin was $0.20 \mathrm{cc}$ in the solution, the voltage difference of the bridge circuit became 4.85 volt. We further added formalin to the solution but the voltage difference was not increased. The output voltages corresponding to different concentrations are summarized in "Table 2".

We plotted output voltages along $\mathrm{x}$ axis and formalin concentration along y axis

Table 2. Output voltage of Wheatstone bridge circuit for different formalin concentration

\begin{tabular}{|c|c|}
\hline $\begin{array}{c}\text { Formalin } \\
\text { Concentration (cc) }\end{array}$ & $\begin{array}{c}\text { Output } \\
\text { voltage } \\
\text { (Volts) }\end{array}$ \\
\hline 0 & 0 \\
\hline 0.02 & 2.19 \\
\hline 0.04 & 2.98 \\
\hline 0.06 & 3.42 \\
\hline 0.08 & 3.60 \\
\hline 0.10 & 3.89 \\
\hline 0.12 & 4.09 \\
\hline 0.14 & 4.38 \\
\hline 0.16 & 4.56 \\
\hline 0.18 & 4.72 \\
\hline 0.20 & 4.85 \\
\hline
\end{tabular}

(Figure 7) in order to find an equation which can give formalin concentration as a function of any output voltage. After adding trend line in formalin concentration versus voltage curve we found the equation of trend line as

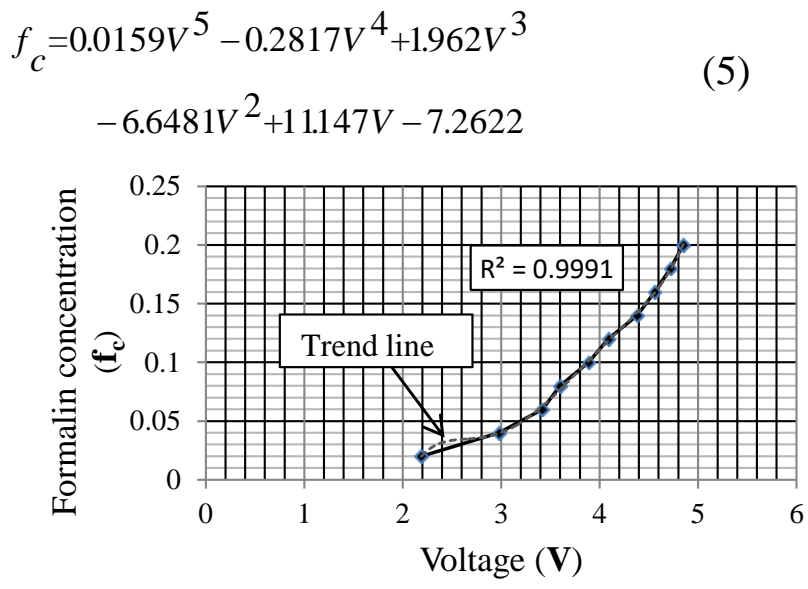

Figure 7. Voltage vs Formalin concentration Curve

From visual inspection we can see that the trend line follows the curve almost exactly. The $\mathrm{R}^{2}$ value is 0.9991 . We measured formalin concentration by following this equation via Arduino code.

\subsection{Formalin concentration measurement using capacitance measurement circuit:}

We used capacitance measurement probe as discussed earlier to measure capacitance for various formalin concentration. The measured capacitance of the solution varied extremely during measurement of lower concentration. When concentration of formalin was increased, measured capacitance variation became less.

Therefore we termed it as measured capacitance range instead of measured capacitance. The measured capacitance ranges corresponding to different concentrations are summarized in "Table 3". As capacitor measurement varied extremely, we used conditional statements for different capacitance range in Arduino to determine the final concentration of formalin. 
Table 3. Capacitance of test solution for different formalin concentration

\begin{tabular}{|c|c|}
\hline $\begin{array}{c}\text { Formalin } \\
\text { Concentration (cc) }\end{array}$ & $\begin{array}{c}\text { Measured } \\
\text { Capacitance Range }\end{array}$ \\
\hline 0 & $800 \mathrm{pF}-8 \mathrm{nF}$ \\
\hline 0.02 & $8 \mathrm{nF}-12 \mathrm{nF}$ \\
\hline 0.04 & $19 \mathrm{nF}-26 \mathrm{nF}$ \\
\hline 0.06 & $70 \mathrm{nF}-96 \mathrm{nF}$ \\
\hline 0.08 & $160 \mathrm{nF}-210 \mathrm{nF}$ \\
\hline 0.10 & $350 \mathrm{nF}-450 \mathrm{nF}$ \\
\hline 0.12 & $28 \mu \mathrm{F}-29 \mu \mathrm{F}$ \\
\hline 0.14 & $29.1 \mu \mathrm{F}-31 \mu \mathrm{F}$ \\
\hline 0.16 & $31.1 \mu \mathrm{F}-35 \mu \mathrm{F}$ \\
\hline
\end{tabular}

\subsection{Final Result}

We combined output of three individual circuits and got the final result. We varied formalin concentration from $0.02 \mathrm{cc}$ to $0.18 \mathrm{cc}$. Actual and measured values from final circuit were compared and summarized in "Table 4". At first, for no formalin in solution, we got $\mathrm{pH}$
6.46. We designed our detection circuit to show no formalin condition for $\mathrm{pH}$ greater than 6.2. So the actual value and measured values are same. For $0.02 \mathrm{cc}$ formalin, $\mathrm{pH}$ value is 5.14 , which is less than 6.2. For this condition, bridge circuit showed output of 2.95 volts. This determined concentration of formalin was $0.04 \mathrm{cc}$. On the other hand; the capacitive circuit gave output of 0cc formalin by showing capacitive output of $13.81 \mathrm{pF}$. It showed no formalin output as the capacitance output is less than its distinguished range of 8-12 nF. After averaging, our detection circuit shows concentration output of 0.02 without showing any error. Overall average error is $7.18 \%$ and for higher concentration of formalin (i.e. greater than $0.08 \mathrm{cc}$ ) the average error is $5.02 \%$.

At first we got enormous percentage of error because we used distilled water for our experiment. Distilled water is termed as hungry water. It has no salt, no minerals. Probably due to this it was affected by sensor probe and environment while the formalin concentration was low. After adding enough formalin to the solution, the fluctuation decreased. The reason may be because formalin was added as impurity and it reaches more towards equilibrium. It decreased percentage of error too.

Table 4. Actual and Measured value of formalin concentration

\begin{tabular}{|c|c|c|c|c|c|c|c|c|}
\hline 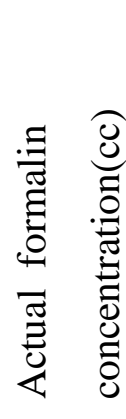 & $\begin{array}{l}\stackrel{0}{J} \\
\stackrel{J}{J} \\
\frac{I}{2}\end{array}$ & 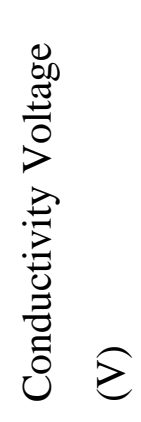 & 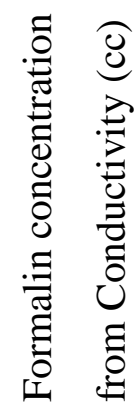 & 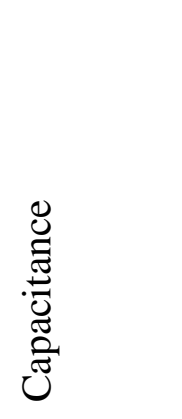 & 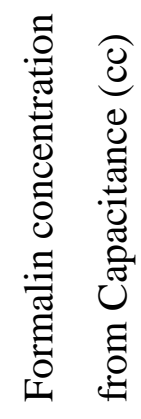 & 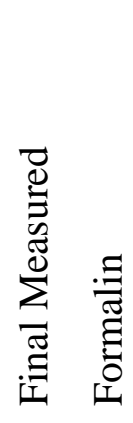 & 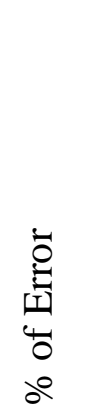 & 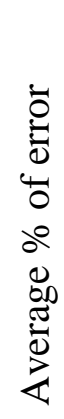 \\
\hline 0 & 6.46 & 0 & 0 & $601.60 \mathrm{pF}$ & 0 & 0 & 0 & \\
\hline 0.02 & 5.14 & 2.95 & 0.04 & $13.81 \mathrm{pF}$ & 0 & 0.02 & 0 & \\
\hline 0.04 & 4.47 & 2.86 & 0.04 & $1018.9 \mathrm{pF}$ & 0.02 & 0.03 & 25 & \\
\hline 0.06 & 4.28 & 3.32 & 0.06 & $12.55 \mathrm{nF}$ & 0.04 & 0.05 & 16.6 & \\
\hline 0.08 & 3.55 & 3.81 & 0.10 & $23.30 \mathrm{nF}$ & 0.06 & 0.08 & 0 & \\
\hline
\end{tabular}




\begin{tabular}{|c|c|c|c|c|c|c|c|c|}
\hline 0.10 & 3.26 & 4.22 & 0.13 & $233.91 \mathrm{nF}$ & 0.08 & 0.11 & 10 & \multirow{5}{*}{7.18} \\
\hline 0.12 & 3.12 & 4.39 & 0.15 & $26.69 \mu \mathrm{F}$ & 0.12 & 0.13 & 8.33 & \\
\hline 0.14 & 3.60 & 4.58 & 0.17 & $28.23 \mu \mathrm{F}$ & 0.12 & 0.14 & 0 & \\
\hline 0.16 & 2.79 & 4.78 & 0.19 & $29.40 \mu \mathrm{F}$ & 0.14 & 0.17 & 6.25 & \\
\hline 0.18 & 1.92 & 4.91 & 0.22 & $31.59 \mu \mathrm{F}$ & 0.16 & 0.19 & 5.55 & \\
\hline
\end{tabular}

We have plunged an apple having formalin on its surface into distilled water for 10 minutes. Then we have taken the apple from water and tested the remaining water. Tested result showed existence of formalin as well as its concentration. We have picked fresh papaya from tree in the yard of our department and plunged into distilled water for 10 minutes. Then we have taken papaya from water afterward tested the remaining water. Tested result showed no formalin.

To find formalin free fruit for testing is difficult. Fruits available in the market are contaminated by formalin even before coming to the market by farmers. Then it might be affected by formalin used for preserving it for long days. But we plucked papaya from tree right in front of our department which is for sure formalin free. So above test result is conclusive.

\section{Conclusions}

In this study, a method consisting three parameters to detect formalin in fruits is demonstrated. The process of detection by this system is simple, reliable although the system is bulky and it takes some time. The detection system also enables to know the quantity of formalin in test solution. Proposed system proved to be an encouraging device for the detection and measurement of formalin. Its size can be reduced by combining all the sensors in same probe. Future works may emphasis on the reduction of the time required and build a robust detection mechanism.

\section{References}

Ali, A.N.M.A., (2013). Food Safety and Public Health Issues in Bangladesh: A Regulatory Concern. European Food and Feed Law Review, 8(1), 31-40.

Arif, M.F.H., Biddut, M.J.H., Ahmed, K., Asaduzzaman, S. (2016). Simulation Based Analysis of Formalin Detection Through Photonic Crystal Fiber. 5th International Conference on Informatics, Electronics and Vision (ICIEV), 776-779.

Coughlin, R.F., Driscoll, F.F. (2001). In: Operational Amplifiers and Linear Integrated Circuits. 6th Ed. Prentice Hall.

Hasan, R.M.M., Dewanjee, A.N., Shemul, S.N. (2014). Design and Construction of a Formalin Detector using the Conductivity Property. 1st National Conference on Electrical \& Communication Engineering and Renewable Energy ECERE 2014. P071.

Hashim, U., Zaki M., Arshad, M.K.M., Ayub, R. M., Fathil, M.F.M., Azman, A.H., Adzhri, R. (2015). Development of electronic reader for formaldehyde detection sensor. 2nd International Conference on Biomedical Engineering (ICoBE).

Khan, U.A., Afsar, M.N. (2007). Measurement of Broadband Dielectric Properties of Cyclohexane, Chlorobenzene, 10\% Formalin, and 1,4-Dioxane Using Dispersive Fourier Transform Spectroscopy. IEEE Transactions on Instrumentation and Measurement, 56(6), 2354-2359.

Möhlmann, G. R. (1985). Formaldehyde Detection in Air by Laser-Induced Fluorescence. Applied Spectroscopy, 39(1), 98-101. 
Sobolev, A.P., Mannina, L., Proietti, N., Carradori, S., Daglia, M., Giusti, A.M., Antiochia R., Capitani, D. (2015). Untargeted NMR-Based Methodology in the Study of Fruit Metabolites. Molecules, 20, 4088-4108.

Tang, X., Mager, N., Vanhorenbeke, B., Hermans, S., Raskin, J.P. (2016). Defectfree functionalized graphene sensor for formaldehyde detection. Nanotechnology, 28(5), 055501.

Wahid, J., Ahsan, Q. (2014). Detection of Impurities in Water by Measuring Capacitance. 8th International Conference on Electrical and Computer Engineering 2014. 88-91.

Zugravu, C. A., Pogurschi, E. N., Patrascu, D., Petronela-Diana, I., Nicolae, C.G. (2017). Attitudes Towards Food Additives: A Pilot Study. The Annals of the University Dunarea de Jos of Galati Fascicle VI - Food Technology, 41(1), 50-61.

\section{Acknowledgment}

The authors would like to appreciate Bangladesh Council of Scientific and Industrial Research (BCSIR), Chittagong, Bangladesh, for their continuous support by providing sample materials 